\title{
A SEX-LINKED VARIANT OF GARGOYLISM
}

\author{
BY
}

\author{
C. GUY MILLMAN and J. W. WHITTICK
}

From the Northgate and District Hospital, Morpeth, Northumberland, and the Department of Pathology, the Royal Cancer Hospital, London

In the condition first described by Hunter (191617) and named "gargoylism" by Ellis, Sheldon, and Capon (1936), opacity of the corneae is, with mental deficiency, osteo-chondro-dystrophic changes, and hepatosplenomegaly, cited as a cardinal sign. That it is not an invariable component of the syndrome has since become evident from the reports of De Lange and Woltring (1936-37), Ross, Hawke, and Brown (1941), De Lange, Gerlings, de Kleyn, and Lettinga (1943-44), Lurie and Levy (1944), Debré, Marie, and Thieffry (1946), and Njå (194546) who describe cases typical in other respects but lacking corneal opacity.

The genetic aspect of gargoylism was investigated by Halperin and Curtis (1942). In reaching the conclusion that the condition is "probably due to the action of a single recessive autosomal gene" these authors, however, make no distinction between cases with corneal opacities and those without. The first indication that there may be a specific variant of gargoylism characterized by clear corneae and a sex-linked heredity appears in a paper by Wolff (1942). Writing from the otological standpoint, she gives the pedigree of a family in America which included four cases, apparently sex-linked, in three generations. One of these is described in some detail, but although lenticular anomalies were noted in the right eye and an abnormality in the disc in the left, the corneae are not specifically mentioned. It is not unreasonable, therefore, to suppose that they were clear.

In 1945-46 Njå described five cases, again without corneal opacities, in a Norwegian family. The pedigree was so strongly suggestive of a sexlinked heredity that this author concluded that it was justifiable to set up a special type, "a sexlinked recessive form where the corneae are clear". This paper describes a group of cases in a family in England which would appear to support this view.

\section{Clinical Report}

The pedigree of our English family is shown in Fig. 1. Nothing is known of the original parents (i, 1 and 2) except that the father was a seafaring man who died " of a stricture" at 47 years and the mother " one of 13 who were all well ". There is no evidence of consanguinity.

As in all previously described gargoyles with clear corneae the sex of our cases was male. No female members of the family exhibited the trait.

The significance of the symbols in Fig. 1 shown in solid black is as follows: Four (ii, 1 and 7 ; iii, 13; and iv, 6) are undoubted cases of the condition under discussion. One (iv, 13) is almost certainly another case though confirmation is lacking. In the remaining case (iii, 7) there can be no more than a suspicion. Little is known of this child and nothing is known of the siblings (iii, 6) or of the descendants, if any, as the family had lost touch with the mother many years ago. The suspicion arises, as the child is said to have been " not quite right", and it is said that his death at 7 years was a " happy release".

The first five of these cases will be described in degrees of detail which vary according to the information available.

Case 1.-This boy (Fig. 1, iv, 6) was known to one of us (C.G.M.) when $7 \frac{1}{2}$ years old and had been under his care from age $11 \frac{1}{2}$ until death at 13 years and 7 months.

The earlier history was that the mother's pregnancy and labour were normal and the child's birth weight $3.85 \mathrm{~kg}$. Mental deficiency was not suspected until towards the end of the first year. The child was unable to sit up at 12 months but walked at 18 months and talked a little at 2 years. Dentition had started at 8 months. At 2 years and 9 months the head circumference was $55 \mathrm{~cm}$., the vertex was high, and the hair coarse. Teeth were rather widely spaced. The back was flat and rigid in appearance when the patient walked. The costal margin was flared and there was a Harrison's sulcus. The liver was palpable but the spleen was not. In the lateral view a radiograph of the spine showed some vertebrae to be ovoid and some to have the hooked processes characteristic of gargoylism.

At $7 \frac{1}{2}$ years the child weighed $19 \cdot 73 \mathrm{~kg}$. and his height was $99 \mathrm{~cm}$. There was no true kyphosis but he walked stiffly, flexed a little at the hips. The head was large 


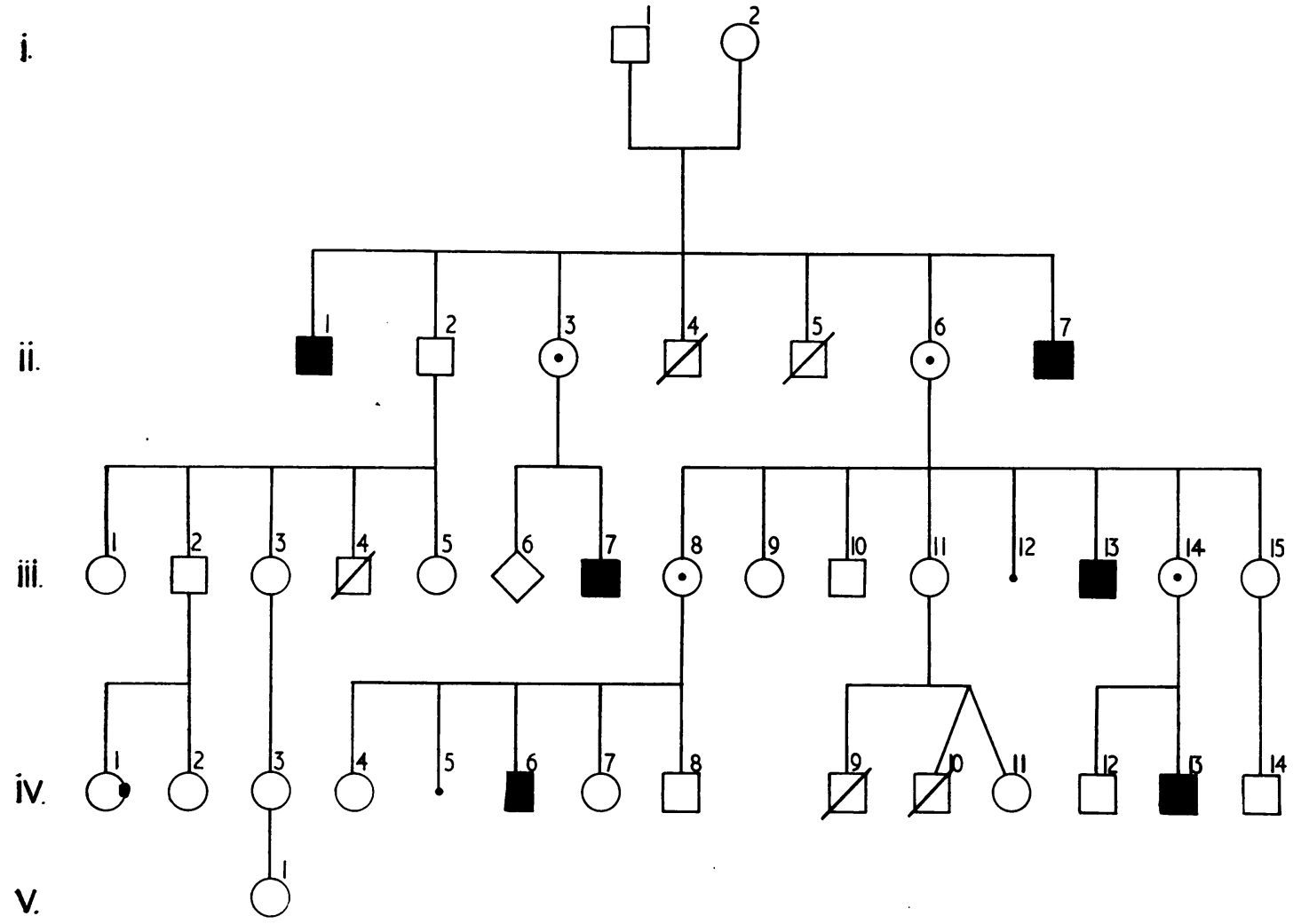
MALE.
7 STILLBORN OR DIED IN INFANCY.
$\bigcirc$ FEMALE.
- presumed carrier.
SIBLINGS, NO. AND SEX UNKNOWN.
- mISCARRIAGE, SEX UNKNOWN.

\section{PRESUMED. OR ESTABLISHED CASES.}

FIG. 1.-Pedigree of affected family.

with frontal bossing; there was a narrow, arched palate and a broad nose with slight depression of the bridge. The ears were placed low. Teeth were healthy but $\frac{6}{6} \mid 6 / 6$ had not yet erupted. The features were heavy and respiration was snuffly. The hair was coarse, the eyebrows bushy, and there was a mild generalized ichthyosis. The liver was enlarged and the abdomen protuberant. There were umbilical and right inguinal herniae and a left hydrocele. There was a loud systolic murmur at the apex of the heart. No corneal opacity was present.

Mentally, at $7 \frac{1}{2}$ years the child remained at a stage of development barely equivalent to the 2-year level; he could say a few words, feed himself, and was clean in habits but he played like a baby.

At $12 \frac{1}{2}$ years deafness was noted but the patient resisted all attempts at otological examination. At this 
time his respiration was noisy and he suffered from a chronic catarrh of the upper respiratory tract. By 13 years a long-standing increase of intracranial pressure had led to some swelling of the optic discs and blurring of their edges. The child's appearance at this age is shown in Fig. 2. By this time he was in a play group at the Cell Barnes Colony school where his histrionic abilities earned him the nickname "Inspector". He was unable to do anything constructive but was fond of giving his imitation of a person writing fluently.

At 13 years and 7 months the patient died suddenly from a combination of causes to be described below.

Case 2.-His disease (Fig. 1, iii, 13) was not diagnosed during life but has been adequately described by his mother and by his sister (the mother of Case 1). Medical notes and a photograph are also available.

That the mental level of this case was rather higher than that of Case 1 is evident from the history. Backwardness was not suspected at such an early age, and at 11 years the child played in a fashion with other children, knew two or three letters, could write a little and be occupied constructively. After leaving a special school at 16 he could help a little in the home and run errands.

Records provide the following information on the physical aspect of the case : At 11 years his height was $120 \mathrm{~cm}$. and the head circumference $54.5 \mathrm{~cm}$. He held his neck very stiffly and was very deaf. By 16 years the child was said to be suffering from heart disease and from "a crippling defect of the fingers". Eighteen months later this was diagnosed as "multiple arthritis of the small joints" and the hips were also becoming involved. Presumably the " arthritis" was the characteristic osseous dystrophy.

An ophthalmologist's report at $18 \frac{1}{2}$ years gives the retinoscopic findings as $+9 \cdot 5 \mathrm{D}$ in each meridian in both eyes and, as no mention is made of the corneae, these are presumed to have been clear.

This patient died suddenly at 21 years of heart trouble. A necropsy is said to have been performed but no records can be traced.

Case 3.-From his sister's description and from the family album we learn that this boy (Fig. 1, ii, 1) was a little taller than Case 1 and had no kyphosis. He had a very large head, " black hair like wire", bushy eyebrows, thick lips, a prominent abdomen, and " no neck; his head rested on his shoulders ". On enquiring as to corneal opacities we are told that he had "beautiful eyes". His mental level was such that he " never went out of doors, used to run about with the broom, was sometimes bad-tempered and would throw things". It is said that he enjoyed looking at newspapers but was almost certainly unable to read. He died at 25 years of dropsy after a month's illness.

Case 4.-From the same sources as in the previous case we learn that this child (Fig. 1, ii, 7) was very small and, at the time of his death from bronchopneumonia at 16 years, was about $91 \mathrm{~cm}$. in height and had a head which, though large, was not as big as his brother's (Case 3), and a "big stomach". He " always seemed to have a cold ". He had bushy eyebrows but fair hair of normal texture. Enquiry as to his eyes elicited the information that they were "sparkling". He went to school until he was 14 but never learned to read or write. He was very simple and of a "sweet disposition".

Case 5.-At present there can be no more than a suspicion regarding this case (Fig. 1, iv, 13) as permission to examine the child has been refused. However, a hospital report at 1 year stated "... keeps his mouth open a lot and sleeps with an open mouth. Tonsils ++ . Appearance rather suggests a mongol but there is no supporting evidence for it other than facial expression ... Harrison's sulcus marked. Sternum indrawn. Frontal bossing. Bridge of nose satisfactory. $X$-ray skull n.a.d." At 14 months a note stated " does not walk yet but crawls and would not stand alone". Suspicion in this case rests on the evidence of osseous abnormalities, unusual appearance, retarded development and, above all, on the opinion of the mother of Case 1 who states that, at 4 years, there is a strong resemblance to her own affected child at the same age.

\section{Necropsy Findings in Case 1}

Necropsy was performed 42 hours after death. The body was that of a stunted boy (height 107.5 $\mathrm{cm}$.: weight $25.5 \mathrm{~kg}$.) of fair muscular development and normal proportions except for a large head and short neck. The bridge of the nose was sunken but there was no prominence of the supra-orbital ridges nor of the mandible. The corneae showed no opacity. There was no kyphosis and no deformity of the hands or feet.

In addition to a protuberant abdomen there was a small empty umbilical hernia (length of sac 1.5 $\mathrm{cm}$. ; orifice $0.9 \mathrm{~cm}$. diam.). The external genitalia were normally developed.

Skeleton.-The skull was considerably enlarged (circumference $57.0 \mathrm{~cm}$; diameters, fronto-occipital $19 \cdot 0$ $\mathrm{cm}$., bi-parietal $14 \cdot 0$, occipitomental $23.0 \mathrm{~cm}$.), and moderately thickened and there was considerable bulging of the orbital roofs into the cranial cavity. No other bony projections into the cranial cavity from the skull base were present. The pituitary fossa was greatly enlarged $(1.9 \mathrm{~cm}$. anteroposteriorly, $1.7 \mathrm{~cm}$. from

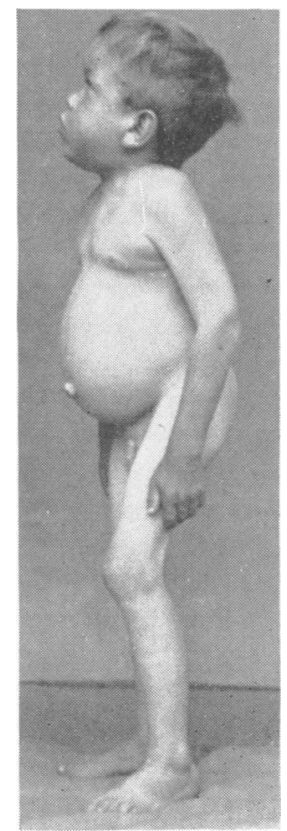

FIG. 2.-Case 1 at 13 years. 
side-to-side, $1.4 \mathrm{~cm}$. deep). Both middle ears contained a small amount of greyish, viscid liquid.

Bilateral grooving on the lower thoracic wall was due to indentation at the costochondral joints of ribs 7 to 9 . There was no thickening of the costochondral junctions.

Some reduction of the normal curvatures of the spine in both thoracic and lumbar regions was evident.

Nervous System.-No abnormality of the dura, which was tense, was found but there was white opacity and prominent thickening of the leptomeninges over the superolateral surfaces of the cerebrum, especially in the neighbourhood of the superior longitudinal venous sinus. The subarachnoid space was distended by clear, pale yellowish liquid. Internal hydrocephalus was pronounced. An enlarged, non-cystic hypophysis filled the pituitary fossa.

Cardiovascular System.-The heart weighed 160.0 g. Its chambers were of normal proportions and the myocardium, which was dark red, had the following maximum thicknesses in the different chambers : left ventricle $1.1 \mathrm{~cm}$., right ventricle $0.4 \mathrm{~cm}$., left atrium $0.3 \mathrm{~cm}$., and right atrium $0.2 \mathrm{~cm}$. All cusps of the aortic and mitral valves were uniformly thickened $(0.2 \mathrm{~cm}$.), rigid, and opaque white. Their surfaces were smooth. The coronary arteries were fully patent and free of atheroma. The foramen ovale was closed. There were a few small opaque yellow flecks of atheroma in the abdominal aorta. Medial to the junction of the left internal jugular and subclavian veins was a multilocular cystic mass $(3.3 \times 1.8 \times 1.2 \mathrm{~cm}$. $)$ containing fresh and partly clotted blood. It was embedded in fat, through which ran small veins communicating with the internal jugular vein.

Respiratory System.-In the naso-pharynx congested polypoid mucosal projections greatly reduced the lumen, and lymphoid tissue in the pharynx was prominent. The palatine tonsils were greatly enlarged and there was considerable narrowing of the glottis caused by oedema of the ary-epiglottic folds.

The upper lobes of the lungs were bound to the thoracic walls by fibrous adhesions. There was uniform congestion of both lungs with thick, greyish mucopus in the bronchi of all lobes.

Lymph Nodes.-One upper deep cervical lymph node on each side was enlarged (larger $3.3 \times 1.8 \times$ $1.2 \mathrm{~cm}$.) and had soft, greyish-white cut surfaces. All other lymph nodes appeared normal.
Alimentary System.-The stomach, grossly distended by greyish liquid, occupied about one-third of the available space in the abdominal cavity. The mucosal surface of its thin wall was closely studded with slightly projecting, miliary and sub-miliary, pale brownish nodules.

There was considerable enlargement of the liver $1,270.0 \mathrm{~g}$.) which in the mid-line extended $11.6 \mathrm{~cm}$. beyond the tip of the xiphoid process, and on the right side $8.0 \mathrm{~cm}$. beyond the costal margin. It was paler than normal, the capsule was tense, and cut surfaces showed very numerous ill-defined, pinkishgrey and opaque white foci of up to $0.3 \mathrm{~cm}$. diameter.

Spleen.-Though enlarged $(13.0 \times 8.4 \times 3.5 \mathrm{~cm}$; $197.0 \mathrm{~g}$.), the spleen was not as large as its position, lower margin $6.0 \mathrm{~cm}$. beyond the costal margin, suggested. This was due partly to displacement by the greatly distended stomach. It was firm and had a thin, smooth-surfaced capsule. On cut surfaces fine trabeculae were distinct but Malpighian bodies were not recognizable, being lost in the pale greyishbrown pulp.

The thymus was enlarged $(10.0 \times 6.5 \times$ up to $1.9 \mathrm{~cm}$. thick; 33.0 g.). No abnormality was found in the adrenals (together $8.7 \mathrm{~g}$.), thyroid $(20.0$ g.), pancreas, kidneys (left 79.0 , right 67.0 g.), ureters, bladder, prostate, and testes (each $3.0 \mathrm{~g}$.).

The sudden death was thought to be due to a combination of cardiac and respiratory failure.

\section{Histological Findings in Case 1}

Spleen.-There was an appreciable amount of diffuse cellular fibrosis: otherwise no special features. No sudanophil material was stainable, no doubly refractile lipoid was present, and no vacuolated cells could be found.

Liver.-Complete derangement of lobular pattern was due to swelling of the hepatic cells, which greatly compressed the sinusoids, and were thrown out of their normal arrangement in columns. The liver cells had thick cytoplasmic walls enclosing pale, sparsely granular cytoplasm in which only small numbers of fine vacuoles were recognizable (Fig. 3). These cells, with Best's carmine stain, gave only a faint positive reaction, indicating that little glycogen was present: it was the granular material which stained positively. Sudan stains for neutral fat showed only small widely scattered groups of small globules. Examined under polarized light, no doubly refractile lipoid could be found. Portal tracts contained small foci of lymphocytic and neutrophilic polymorph infiltration and occasional small groups of multinucleate giant cells. 


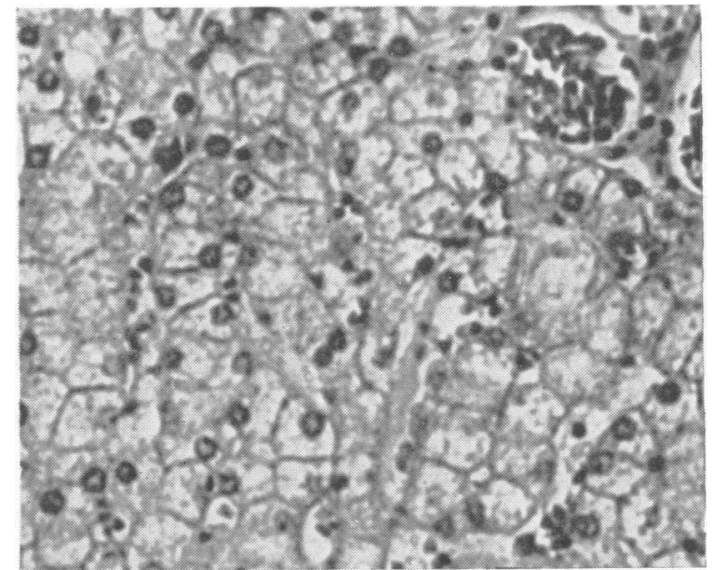

FIG. 3.-Swollen hepatic cells with pale, granular cytoplasm compressing and obliterating sinusoids. $\times 320$.

Costochondral Junction.-There was an almost completely static straight line with practically no proliferation of cartilage, a very narrow zone of provisional calcification of cartilage, and little osteoblastic or osteoclastic activity (Fig. 4). A striking change was the presence of a thick layer of pale-staining, fibrous tissue between the thick periosteum and the irregular bony corticalis of the

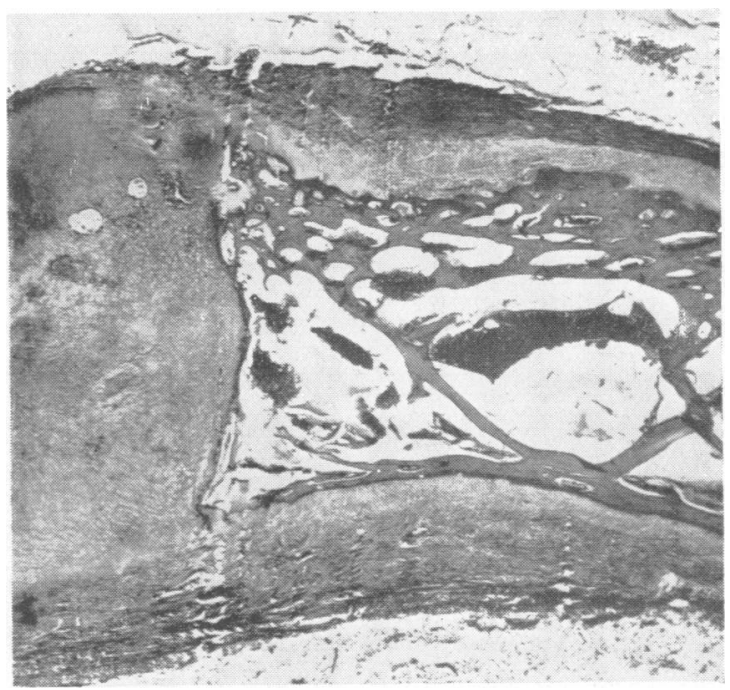

Fig. 4.-Costochondral junction showing almost complete arrest of endochondral ossification and thickened periosteum. $\times 7$.

rib. The collagenous fibrillae in this layer ran obliquely between the corticalis and the periosteum and were separated by fairly numerous, irregularly scattered clear cells, in the cytoplasm of some of which was a small amount of pale-staining granular material (Fig. 5). Clear cells of the same type, though less numerous, were present throughout the periosteum. In sections treated with Sudan III, Sudan black B, and by the periodic-acid-Schiff method these pale cells failed to stain.

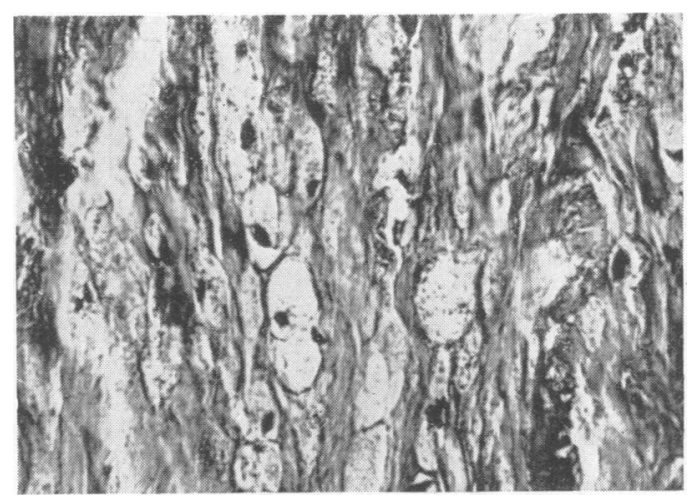

Fig. 5.- "Clear" cells scattered through the thickened periosteum of a rib. $\times 320$.

Pituitary.-Enlargement was due to an increase in size of the anterior lobe where there was a paucity of eosinophilic cells and a relative increase in the number of cells with basophilic granules. The commonest cell was a degenerate one with finely vacuolated pale cytoplasm which appeared to be derived from the basophilic cells.

Heart.-Thickening of the mitral cusps was due to dense, poorly cellular fibrous tissue. Much of the collagen stained poorly by van Gieson's method. Between the collagen fibres there were fairly numerous, pale, ovoid cells with small, usually pyknotic nuclei and finely vacuolated or granular cytoplasm (Fig. 6). They were identical in appearance with the clear cells in and below the periosteum of the ribs.

There was no abnormality in the myocardium.

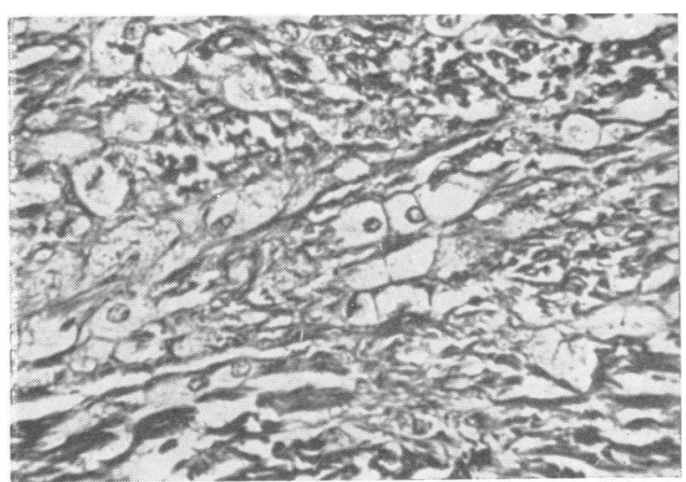
FIG._6.-Separation of collagenous tissue in a mitral cusp by large
"clear" cells. $\times 320$. 
Lymphoid Tissue. - The polypoid mucosal thickenings of the naso-pharynx, the palatine tonsils, and the upper deep cervical lymph nodes all showed great lymphoid hyperplasia and subacute inflammatory changes.

The fine nodularity in the gastric mucosa was due to the presence of lymphoid follicles.

Eye.-No abnormality was present.

Left Supraclavicular Tumour.-This consisted of a congeries of large vascular spaces containing blood and embedded in fibrous and adipose tissue in which there were small lymph nodes. Acute inflammatory changes were superimposed.

Lung.-Long-standing chronic bronchitis and acute congestion were present.

Thymus.-Glandular thymus was of normal structure except for collections of neutrophilic polymorphs in and about Hassall's corpuscles.

No significant abnormality was present in sections of the kidneys, prostate, testes, thyroid, parathyroids (two examined), and adrenals.

Unfortunately mishap overtook the stored brain, vertebrae, and long bones, so that these were not available for further examination

\section{Discussion}

Published accounts of necropsy findings in cases of gargoylism are few. Strauss (1948), in a complete review of the literature, refers to descriptions of the pathological changes in 15 cases but notes that several are incomplete and some are doubtful instances of gargoylism. She adds a new case, and Russell (1949) in her monograph on hydrocephalus mentions another. Of these 17 gargoyles only two were of the type with clear corneae (De Lange and others, 1943-44 ; Njå, 1945-46).

While we are unable to give a complete description of the pathological changes in Case 1, our findings allow confirmation of the clinical diagnosis of gargoylism and raise points of interest. Because of Strauss's recent review, only a few of these will be referred to briefly.

With the material available, it was not possible to demonstrate the presence of lipoid, though large, pale cells with vacuolated finely granular cytoplasm, resembling those illustrated by Strauss, were present in the thickened cusps of the mitral valve and in the widened periosteum of a rib. Cytoplasmic changes of similar appearance were present in the distended hepatic cells but in none of the other organs examined microscopically. The cornea and other parts of the eye were normal.
The skeletal abnormalities in our case resemble those described in other gargoyles, and the histological finding of arrest of ossification at the costochondral junctions with periosteal thickening and infiltration by vacuolated cells is very similar to that of Strauss. Though no differential count of the cells of the anterior pituitary was made, the impression was gained from examination of sections that there was a reduction in the number of cells with eosinophil granules. Till this is confirmed by other necropsy studies its possible relationship to the characteristic dwarfism of gargoyles can be only tentatively suggested.

Thickening and rigidity of the cusps of the mitral and aortic valves have been described previously, and our findings and views are very similar to those of Strauss who regards the change as due not to endocarditis but to the accumulation of vacuolated cells and fibrosis. The common occurrence of sudden death due to heart failure is probably related to these valvular lesions.

There is in our case no support for Strauss's opinion that when hydrocephalus occurs in gargoyles it is due to compression of the brain stem by bony elevations at the base of the skull. As in Russell's case, ours showed thickening of the leptomeninges over the superior surfaces of the cerebral hemispheres and no bony compression of the brain stem. Her explanation that hydrocephalus results from this leptomeningeal fibrosis is supported by our findings but we were unfortunately unable to examine the meninges histologically for the lipoidal material which she describes within the arachnoid cells. Njå's Case 2, which had clear corneae, also showed hydrocephalus associated with " thickened and milky" leptomeninges.

\section{Summary}

In three generations of an English family, four and possibly five cases of gargoylism, in which corneal opacity was lacking, are described. All five subjects were males and they appeared to inherit the condition as a sex-linked recessive character.

The necropsy findings in one of these cases are described.

We wish to express our gratitude to Dr. Noel H. M. Burke, Medical Superintendent, Cell Barnes Colony, for permission to publish the details of Case 1 , and for his encouragement and assistance. We are indebted to Dr. A. Shapiro for calling our attention to the families described by Wolff and by $\mathrm{Njåa,} \mathrm{whose} \mathrm{reports} \mathrm{we} \mathrm{had}$ not yet seen when our own investigations were finished. To Professor L. S. Penrose we extend our thanks for his encouragement and advice on the genetic aspect of the 
work. We are indebted to Dr. W. G. Wyllie for notes on the earlier history of Case 1 and to Dr. W. Templeton for giving access to the notes on Case 2. We also wish to thank Mr. A. E. Reynolds for the photograph and Mr. L. A. Cowles for the photomicrographs. Finally we would place on record, with gratitude, the help given by many members of the family we have described.

\section{REFERENCES}

Debré, R., Marie, J., and Thieffry, S. (1946). Sem. Hôp. Paris, 22, 309.

De Lange, C., Gerlings, P. G., de Kleyn, A., and Lettinga, T. W. (1943-44). Acta paediat., Uppsala, 31, 398.

$\longrightarrow$, and Woltring, L. (1936-37). Ibid., 19, 71.

Ellis, R. W. B., Sheldon, W., and Capon, N. B. (1936). Quart. J. Med., 29, (n.s. 5), 119 .

Halperin, S. L., and Curtis, G. M. (1942). Amer. J. ment. Defic., 46, 298.

Hunter, C. (1916-17). Proc. roy. Soc. Med., 10, (Sect. Study Dis. Child.), 104

Lurie, L. A., and Levy, S. (1944). Amer. J. med. Sci., 207, 184.

$\mathrm{Njå,} \mathrm{A.} \mathrm{(1945-46).} \mathrm{Acta} \mathrm{paediat.,} \mathrm{Uppsala,} \mathrm{33,} 267$.

Ross, J. R., Hawke, W. A., and Brown, A. (1941). Arch. Dis. Childh., 16, 71 .

Russell, D. S. (1949). Spec. Rep. Ser. med. Res. Coun., Lond., no. 265 , p. 52

Strauss, L. (1948). Amer. J. Path., 24, 855.

Wolff, D. (1942). Laryngoscope, St. Louis, 52, 218.

\section{Addendum}

Since dispatching our paper we have received from Dr. Ivor Balfour the following further details of Case 5 which he examined at 5 years and considered to be one of gargoylism :

Height $99 \mathrm{~cm}$.; weight $16.4 \mathrm{~kg}$.; head circumference $52 \mathrm{~cm}$. Marked supra-orbital ridges. Broad alae nasi and nasal discharge.

Ears low on head. Thick neck. ? early kyphosis. Genu valgum. Broad hands; terminal phalanges cannot be extended, i.e. claw fingers. No corneal opacities. Apparently some mental retardation.

A radiograph showed considerable enlargement of the sella turcica, especially the antero-posterior measurement; some thickening of bones on either side of the coronal sutures, but no evidence of the other characteristic bony changes reported in the literature.

Abdomen was distended; umbilical hernia. Liver and spleen enlarged and easily palpable.

Blood cholesterol $140 \mathrm{mg} . \%$. W.R. negative. White blood count 4,400 , and 3,300 on the two occasions tested. Giemsa-Wright stain (Reilly method) showed no pink granules. 